\title{
Aeroacoustic Experiments With Twin Jets
}

Richard F. Bozak and Brenda S. Henderson

Glenn Research Center, Cleveland, Ohio 


\section{NASA STI Program . . . in Profile}

Since its founding, NASA has been dedicated to the advancement of aeronautics and space science. The NASA Scientific and Technical Information (STI) program plays a key part in helping NASA maintain this important role.

The NASA STI Program operates under the auspices of the Agency Chief Information Officer. It collects, organizes, provides for archiving, and disseminates NASA's STI. The NASA STI program provides access to the NASA Aeronautics and Space Database and its public interface, the NASA Technical Reports Server, thus providing one of the largest collections of aeronautical and space science STI in the world. Results are published in both non-NASA channels and by NASA in the NASA STI Report Series, which includes the following report types:

- TECHNICAL PUBLICATION. Reports of completed research or a major significant phase of research that present the results of NASA programs and include extensive data or theoretical analysis. Includes compilations of significant scientific and technical data and information deemed to be of continuing reference value. NASA counterpart of peer-reviewed formal professional papers but has less stringent limitations on manuscript length and extent of graphic presentations.

- TECHNICAL MEMORANDUM. Scientific and technical findings that are preliminary or of specialized interest, e.g., quick release reports, working papers, and bibliographies that contain minimal annotation. Does not contain extensive analysis.

- CONTRACTOR REPORT. Scientific and technical findings by NASA-sponsored contractors and grantees.
- CONFERENCE PUBLICATION. Collected papers from scientific and technical conferences, symposia, seminars, or other meetings sponsored or cosponsored by NASA.

- SPECIAL PUBLICATION. Scientific, technical, or historical information from NASA programs, projects, and missions, often concerned with subjects having substantial public interest.

- TECHNICAL TRANSLATION. Englishlanguage translations of foreign scientific and technical material pertinent to NASA's mission.

Specialized services also include creating custom thesauri, building customized databases, organizing and publishing research results.

For more information about the NASA STI program, see the following:

- Access the NASA STI program home page at http://www.sti.nasa.gov

- E-mail your question via the Internet to help@ sti.nasa.gov

- Fax your question to the NASA STI Help Desk at $443-757-5803$

- Telephone the NASA STI Help Desk at 443-757-5802

- Write to: NASA Center for AeroSpace Information (CASI) 7115 Standard Drive Hanover, MD 21076-1320 
NASA/TM-2012-217249

AIAA-2011-2790

\section{Aeroacoustic Experiments With Twin Jets}

Richard F. Bozak and Brenda S. Henderson

Glenn Research Center, Cleveland, Ohio

Prepared for the

17th Aeroacoustics Conference

cosponsored by the American Institute of Aeronautics and Astronautics and

the Confederation of European Aerospace Societies

Portland, Oregon, June 5-8, 2011

National Aeronautics and

Space Administration

Glenn Research Center

Cleveland, Ohio 44135

February 2012 


\section{Acknowledgments}

This work was funded by the Subsonic Fixed Wing and Supersonics Projects of NASA's Fundamental Aeronautics Program.

Trade names and trademarks are used in this report for identification only. Their usage does not constitute an official endorsement, either expressed or implied, by the National Aeronautics and Space Administration.

This work was sponsored by the Fundamental Aeronautics Program at the NASA Glenn Research Center.

Level of Review: This material has been technically reviewed by technical management.

Available from

NASA Center for Aerospace Information 7115 Standard Drive

Hanover, MD 21076-1320
National Technical Information Service 5301 Shawnee Road Alexandria, VA 22312

Available electronically at http://www.sti.nasa.gov 


\title{
Aeroacoustic Experiments With Twin Jets
}

\author{
Richard F. Bozak and Brenda S. Henderson \\ National Aeronautics and Space Administration \\ Glenn Research Center \\ Cleveland, Ohio 44135
}

\begin{abstract}
While the noise produced by a single jet is azimuthally symmetric, multiple jets produce azimuthally varying far-field noise. The ability of one jet to shield another reduces the noise radiated in the plane of the jets, while often increasing the noise radiated out of the plane containing the jets. The present study investigates the shielding potential of twin jet configurations over subsonic and over-expanded supersonic jet conditions with simulated forward flight. The experiments were conducted with 2 in. throat diameter nozzles at four jet spacings from $2.6 d$ to $5.5 d$ in center-to-center distance, where $d$ is the nozzle throat diameter. The current study found a maximum of $3 \mathrm{~dB}$ reduction in overall sound pressure level relative to two incoherent jets in the peak jet noise direction in the plane containing the jets. However, an increase of $3 \mathrm{~dB}$ was found perpendicular to the plane containing the jets. In the sideline direction, shielding is observed for all jet spacings in this study.
\end{abstract}

\section{Introduction}

Several subsonic and supersonic vehicles in the current fleet have multiple engines mounted near one another. Some future vehicle concepts may use innovative propulsion systems such as distributed propulsion which will result in multiple jets mounted in close proximity. Engine configurations with multiple jets have the ability to exploit jet-by-jet shielding which may significantly reduce noise. Jet-byjet shielding is the ability of one jet to shield noise that is emitted by another jet. The current study investigates the noise shielding potential of a twin jet configuration.

Full and small scale twin jet aeroacoustic experiments were documented throughout the 1970s. Full scale static tests of the XB-70 found that effects of shielding depended mainly on the observation angle. The results showed that shielding occurs at high frequencies. For subsonic jets, engine spacing had no shielding effect (Ref. 1). However, extensive small scale static experiments showed that the frequencies where shielding occurred depended on the jet spacing (Ref. 2). The apparent discrepancy between the full and small scale results may be due to the limited full scale data set. Additionally in small scale experiments, azimuthal measurements show mixing suppression in addition to the shielding for closely spaced jets (Ref. 2).

In the 1980s, an analytical model was used to explain the directivity of jet-by-jet shielding when jet spreading was taken into account (Refs. 3 and 4). At angles near the jet axis, shielding was most effective due to the spreading of the jet and the lack of sound transmission through the jet. The theoretical limit of transmission through the jet was given by the transmission cut-off angle (Ref. 5). At polar angles between the jet axis and the cut-off angle no sound is transmitted from one jet through the shear layer of the other jet.

The present study investigates the aeroacoustics of twin jets over subsonic and over-expanded supersonic jet conditions for simulated forward flight Mach numbers from 0 to 0.3 and jet spacings from $2.6 d$ to $5.5 d$, where $d$ is the nozzle throat diameter. Two inch throat diameter jets were used in the experiments. The magnitudes of jet-by-jet shielding and interaction are analyzed. The frequency dependence of the jet-by-jet shielding is also investigated. 


\section{Experimental Setup}

The experiments were conducted in the Aero-Acoustic Propulsion Laboratory (AAPL) at NASA Glenn Research Center shown in Figure 1. The AAPL is a $65 \mathrm{ft}$ radius hemi-anechoic dome containing the Nozzle Acoustic Test Rig (NATR). The NATR (shown in Figure 2) is a 53 in. free jet wind tunnel, used to simulate forward flight, capable of achieving a maximum Mach number of 0.35 . The High Flow Jet Exit Rig (HFJER) is a dual stream jet engine simulator mounted in the center of the NATR. The HFJER provides heated core and bypass flow to simulate common engine exhausts (Ref. 6).

A far-field overhead microphone array contains 24 microphones on a $45 \mathrm{ft}$ arc covering polar angles from $45^{\circ}$ to $160^{\circ}$ relative to the inlet axis of the nozzle. For all data presented, microphone sensitivity, actuator, and diffraction corrections have been made. Background noise has been subtracted and free jet shear layer corrections have been applied using Amiet's method (Ref. 7). Atmospheric attenuation effects have been removed (Ref. 8) and the data are presented in $1 / 12^{\text {th }}$ octave bands propagated to a 1-ft lossless arc.

The twin jet model was mounted on the core stream of the HFJER. A model of the twin jet model is shown in Figure 3. The y-duct divides the core flow from the dual stream HFJER into two streams. The internal pressure taps shown at the inlet to the s-ducts monitor the pressure in each leg of the twin jet model to ensure equal flow through each nozzle. The s-ducts following the y-duct are used to vary the spacing between the nozzles. The straight adapter was used to obtain parallel flow through the nozzles. For subsonic jet exhausts, 2 in. throat diameter convergent conical nozzles are attached to the straight adapter, while 2 in. throat diameter contoured convergent-divergent nozzles with a design Mach number of 1.52 were used for supersonic exhausts. The four nozzle spacings used in the experiments are shown in Table I as a ratio of the center-to-center spacing, $s$, to the nozzle throat diameter, $d$. Single jet measurements were made with a conical plug on one jet.

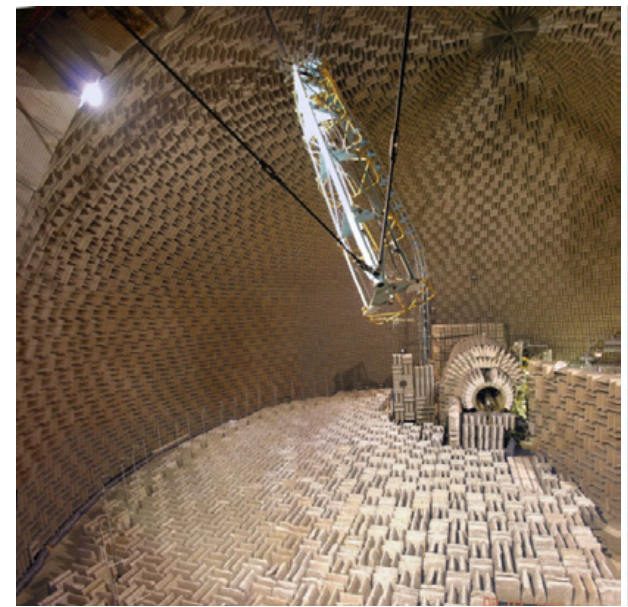

Figure 1.-Aero-Acoustic Propulsion Laboratory (AAPL).

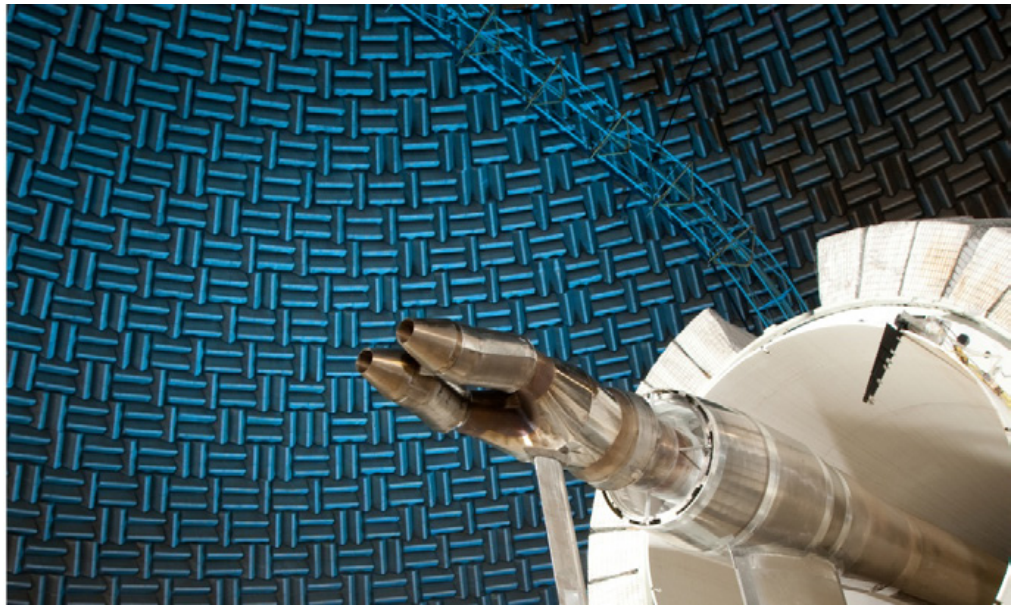

Figure 2.-Twin jet model installed on the High Flow Jet Exit Rig (HFJER) in the Nozzle Acoustic Test Rig (NATR).

TABLE I.-TWIN JET SPACINGS

\begin{tabular}{|c|c|}
\hline $\begin{array}{c}\text { Spacing } \\
\text { designation }\end{array}$ & s/d \\
\hline S1 & 2.625 \\
S3 & 3.245 \\
S5 & 4.39 \\
S8 & 5.54 \\
\hline
\end{tabular}




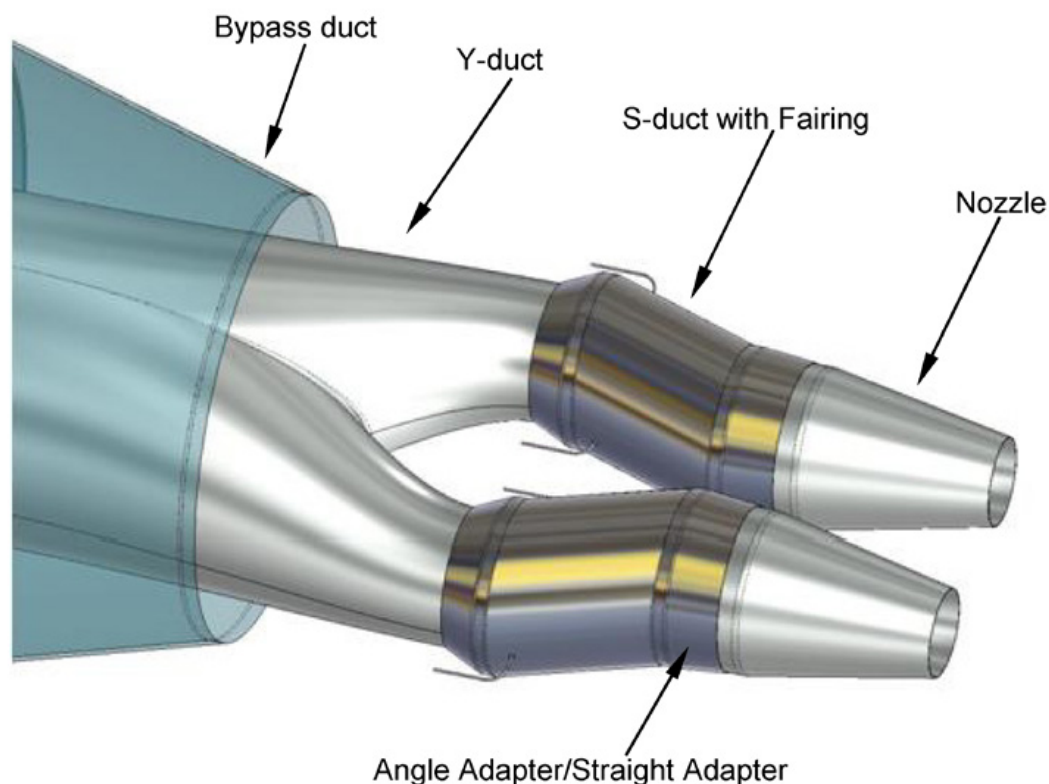

Figure 3.-Twin jet model components.

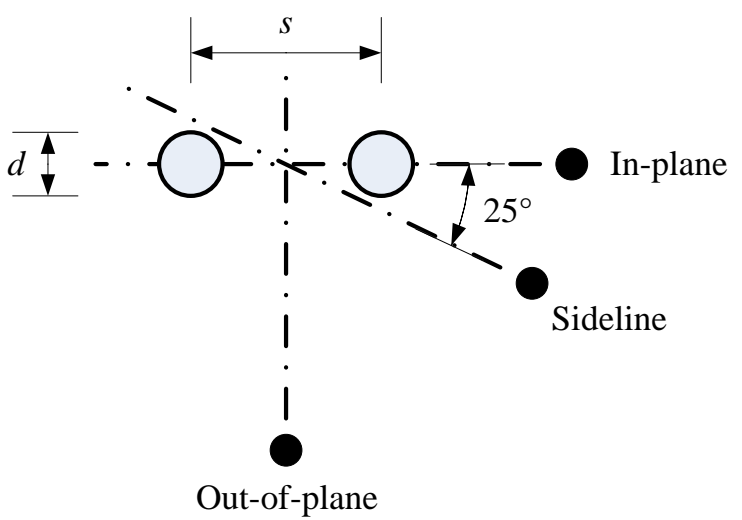

Figure 4.-Azimuthal directivity microphone measurement positions, relative to the jet throats.

Acoustic data were acquired at the three azimuthal angles shown in Figure 4, where the black dots represent the axis of the microphone array. In the plane of the two jets, the acoustic radiation from one jet can be shielded by the other jet. The acoustic radiation from both jets and the acoustic effects of plume interaction can be measured out of the plane containing the two jets. The sideline position represents an orientation used for Federal Aviation Administration sideline takeoff noise measurements, which is approximately $25^{\circ}$ from the shielding direction.

The jet operating conditions used in the experiments are shown in Table II. Nozzle pressure ratios (NPR) from 1.5 to 3.7, nozzle temperature ratios (NTR) from 1.0 to 3.1, and free jet Mach numbers ( $\mathrm{M}_{\mathrm{fj}}$ ) from 0 to 0.3 were used in the experiments. The nozzle pressure ratios were calculated as a ratio of the jet stagnation pressure to the atmospheric pressure. The nozzle temperature ratios were calculated as the ratio of the jet stagnation temperature to the ambient temperature. The jet operating conditions used with the convergent nozzles include over-expanded, under-expanded, and ideally expanded conditions. The conditions used with the contoured convergent-divergent nozzles cover a range of over-expanded conditions and an ideally expanded condition. Since the single stream model was mounted to a dual stream rig, the conditions of the bypass stream were matched to those of the free jet. 


\begin{tabular}{|c|c|c|c|}
\hline & NPR & NTR & $\mathrm{M}_{\mathrm{fj}}$ \\
\hline \multirow{15}{*}{ 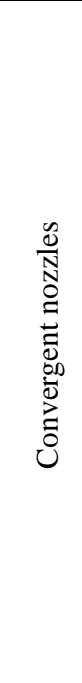 } & 1.86 & 1.00 & 0.00 \\
\hline & 1.86 & 1.00 & 0.10 \\
\hline & 1.70 & 3.11 & 0.00 \\
\hline & 1.70 & 3.11 & 0.10 \\
\hline & 1.52 & 1.95 & 0.10 \\
\hline & 1.51 & 2.57 & 0.10 \\
\hline & 1.69 & 2.08 & 0.10 \\
\hline & 1.67 & 2.85 & 0.10 \\
\hline & 1.89 & 1.00 & 0.10 \\
\hline & 1.88 & 2.37 & 0.10 \\
\hline & 1.87 & 3.12 & 0.10 \\
\hline & 2.01 & 1.00 & 0.10 \\
\hline & 2.00 & 2.51 & 0.10 \\
\hline & 1.87 & 3.12 & 0.30 \\
\hline & 2.00 & 2.51 & 0.30 \\
\hline \multirow{10}{*}{ 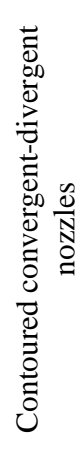 } & 2.00 & 2.40 & 0.10 \\
\hline & 2.50 & 2.80 & 0.10 \\
\hline & 3.00 & 3.00 & 0.10 \\
\hline & 3.50 & 3.00 & 0.10 \\
\hline & 3.70 & 3.10 & 0.10 \\
\hline & 2.00 & 2.40 & 0.30 \\
\hline & 2.50 & 2.80 & 0.30 \\
\hline & 3.00 & 3.00 & 0.30 \\
\hline & 3.50 & 3.00 & 0.30 \\
\hline & 3.70 & 3.10 & 0.30 \\
\hline
\end{tabular}

\section{Results}

The shielding and interaction effects are first analyzed at the in-plane and out-of plane positions shown in Figure 4. The results obtained at these model orientations are then used to determine the polar angle directivity at three free jet Mach numbers. The azimuthal angle directivity is determined by analyzing the data from all three model orientations shown in Figure 4. To evaluate the shielding and interaction effects, twin jet data are compared against data for a single jet and a single jet plus a level increase of $3 \mathrm{~dB}$, referred to as "single jet plus $3 \mathrm{~dB}$." A single jet plus $3 \mathrm{~dB}$ represents the addition of two incoherent jets. When one jet is entirely shielded by the other jet, the levels measured for the twin jets will equal those for the singe jet. When no shielding or interaction effects are observed, the levels for the twin jets will equal those for the single jet plus $3 \mathrm{~dB}$. Interaction effects are defined as a change in sound pressure level from the single jet plus $3 \mathrm{~dB}$ level which can be attributed to jet plume interactions or acoustic interactions between the jets.

Subsonic conditions are evaluated at polar angles of $90^{\circ}$ and $150^{\circ}$ to show the effects of the twin jet configuration on acoustic radiation at the broad side and peak jet noise directions. Supersonic conditions are evaluated at polar angles of $60^{\circ}$ and $150^{\circ}$ to show the effects of the twin jet configuration on acoustic radiation at the broadband shock noise and the peak jet noise directions. The $1 / 12^{\text {th }}$ octave band sound pressure levels obtained at each spacing in Table I are compared to the levels of a single jet and single jet plus $3 \mathrm{~dB}$ to evaluate shielding effects and compared only to the single jet plus $3 \mathrm{~dB}$ levels to evaluate interaction effects. 
Overall sound pressure levels are used to evaluate both polar and azimuthal directivity. The difference in OASPL between the twin configuration and a single jet plus $3 \mathrm{~dB}$ is referred to as $\triangle \mathrm{OASPL}$. The polar directivity from both the shielding and interaction positions are evaluated between free jet Mach numbers of 0 and 0.3 . The azimuthal directivity is evaluated by comparing all three positions shown in Figure 4 to a single jet plus $3 \mathrm{~dB}$ for each jet spacing.

\section{Shielding}

Shielding effects are evaluated for heated subsonic and over-expanded supersonic jet conditions with a free jet Mach number of 0.1 at the in-plane azimuthal angle. Figure 5 shows the spectra of heated subsonic jets in the shielding position. At a polar angle of $90^{\circ}$, no shielding is seen below $4 \mathrm{kHz}$ while partial shielding is evident above $4 \mathrm{kHz}$. Acoustic radiation is not sensitive to jet spacing at this polar angle. In the peak polar jet noise direction of $150^{\circ}$, sound pressure levels at frequencies below $3 \mathrm{kHz}$ are partially shielded, while the levels for frequencies over $3 \mathrm{kHz}$ are completely shielded. More shielding is observed for a $s / d$ of 2.625 (S1) than any other jet spacing. The shielding obtained at this spacing surpasses complete shielding for frequencies above $2.5 \mathrm{kHz}$ by approximately $1 \mathrm{~dB}$. A variation in sound pressure level with spacing is evident over all frequencies. The shielding trends shown in Figure 5 are consistent over all subsonic jet conditions in Table II.

Figure 6 shows the spectra of heated over-expanded supersonic jets in the plane containing the jets. At a polar angle of $60^{\circ}$, the broadband shock noise peak is seen at $7 \mathrm{kHz}$. The twin jet noise levels are unshielded over all frequencies with the exception of the s/d of 5.54 (S8). For the S8 spacing, $1 \mathrm{~dB}$ of shielding is evident for frequencies over $9 \mathrm{kHz}$. At a polar angle of $150^{\circ}$, complete shielding exists below $3 \mathrm{kHz}$ for the all jet spacings, while partial shielding of $2 \mathrm{~dB}$ is seen over all other frequencies. The shielding trends shown in Figure 6 are consistent with results obtained at all supersonic jet conditions shown in Table II.

(a)

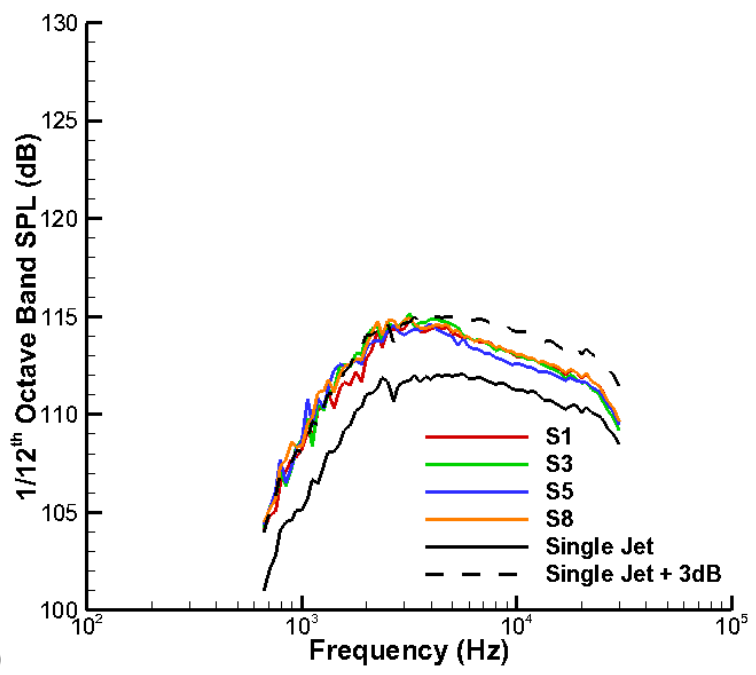
and (b) $150^{\circ}$.

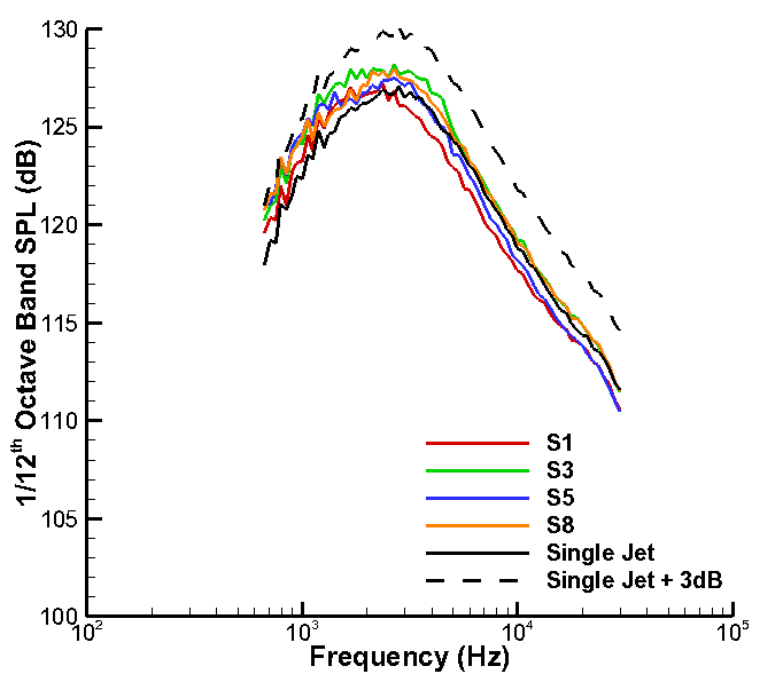

(b) (a) $90^{\circ}$ 

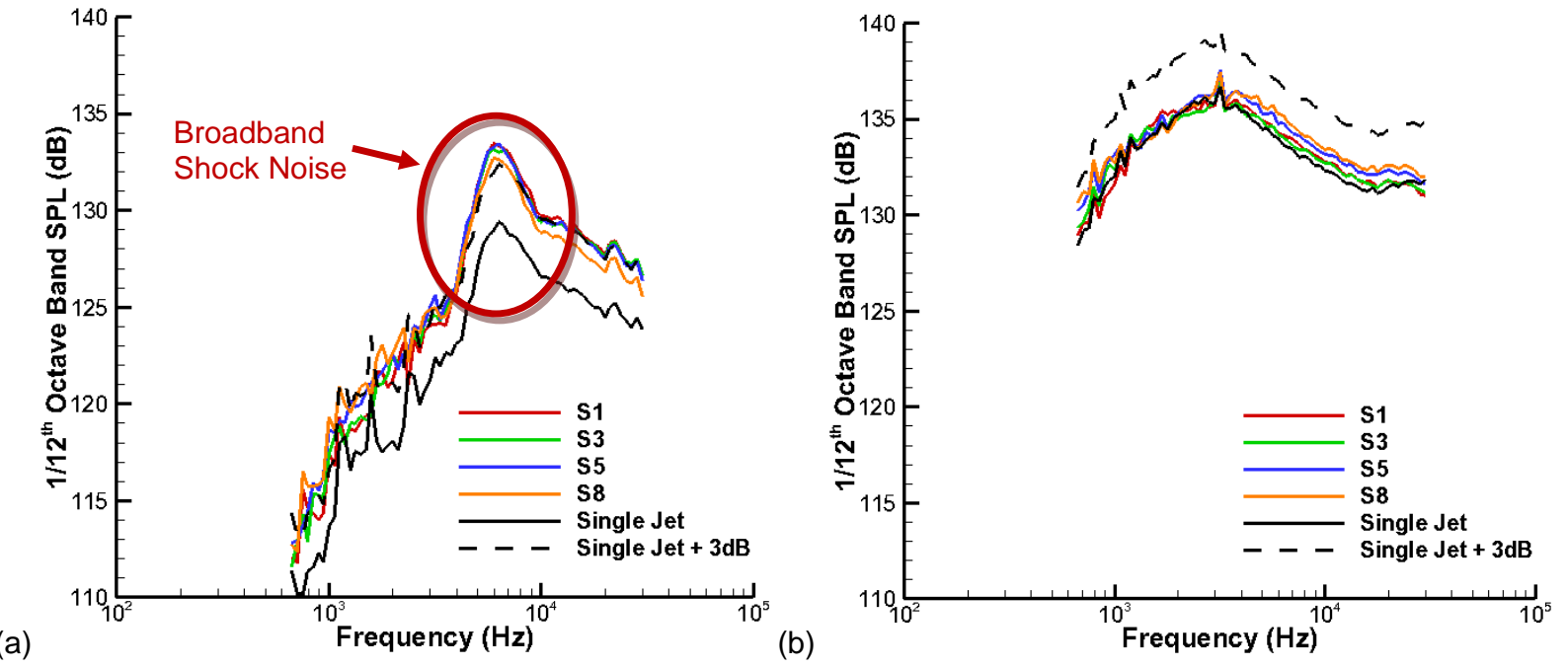

Figure 6.-Shielding of heated supersonic jets with NPR=3.0, NTR=3.0, and $\mathrm{M}_{\mathrm{fj}}=0.1$ at polar angles (a) $60^{\circ}$ and (b) $150^{\circ}$.
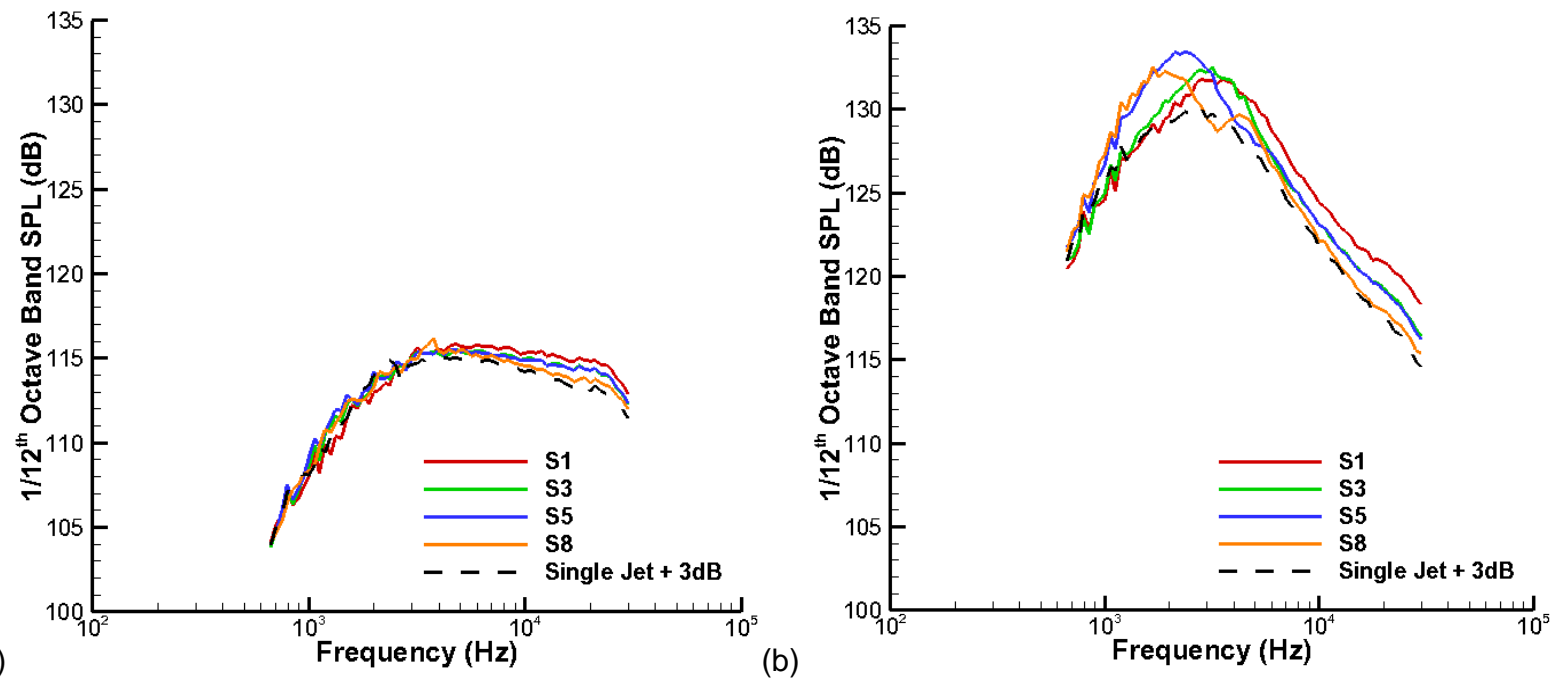

Figure 7.- Interaction of heated subsonic jets with NPR=1.88, NTR=2.37, and $\mathrm{M}_{\mathrm{fj}}=0.1$ at polar angles (a) $90^{\circ}$ and (b) $150^{\circ}$.

\section{Interaction}

Interaction effects are evaluated for heated subsonic and over-expanded supersonic jet conditions with a free jet Mach number of 0.1. Figure 7 shows the spectra of heated subsonic jets out of the plane containing the jets. At a polar angle of $90^{\circ}$, no interaction effects are evident for frequencies less than $6 \mathrm{kHz}$. However, from 6 to $30 \mathrm{kHz}$ interaction effects increase with increasing frequency. The interaction effects increase the noise levels with decreasing jet spacing. At a polar angle of $150^{\circ}$, interaction effects are seen for all frequencies greater than $1 \mathrm{kHz}$ at all jet spacings. At a s/d of 5.54 (S8), a secondary peak appears at $4 \mathrm{kHz}$ and no interaction effects are seen above $6 \mathrm{kHz}$. The interaction effects are concentrated near the peak frequency where an increase of up to $4 \mathrm{~dB}$ is evident. The peak frequencies for the $\mathrm{S} 1$ and S3 jet spacings are slightly higher than that of the single jet plus $3 \mathrm{~dB}$ while those of the S5 and S8 jet spacings are slightly lower. The interaction effects in the peak jet noise direction are sensitive to jet spacing. The interaction trends shown in Figure 7 are representative of all subsonic jet conditions in Table II. 

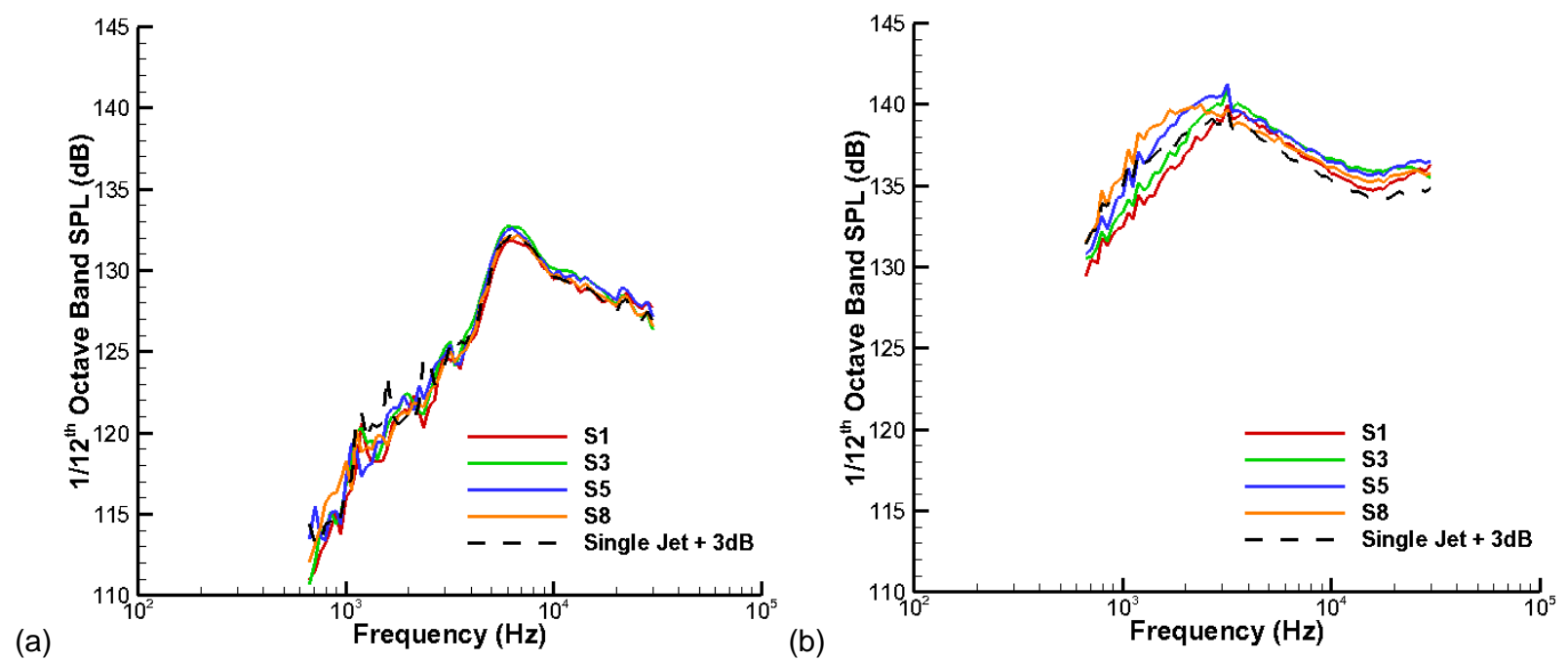

Figure 8.- Interaction of heated supersonic jets with NPR=3.0, NTR=3.0, and $\mathrm{M}_{\mathrm{fj}}=0.1$ at polar angles (a) $60^{\circ}$ and (b) $150^{\circ}$.

Figure 8 shows the spectra of heated over-expanded supersonic jets at the out-of-plane azimuthal angle. At a polar angle of $60^{\circ}$, all twin jet noise levels, including the broadband shock noise, are not affected by interaction effects for any jet spacing. At a polar angle of $150^{\circ}$, the noise levels of the $\mathrm{S} 1$ and S3 jet spacings are below those for the single jet plus $3 \mathrm{~dB}$ for frequencies below $3 \mathrm{kHz}$. This reduction in noise level may be attributed to enhanced mixing, as seen in similar experiments (Ref. 2). The noise level increase for the S5 and S8 jet spacings show interaction effects up to $2 \mathrm{~dB}$ between 1.5 and $3 \mathrm{kHz}$. Above $3 \mathrm{kHz}$ an interaction effect increase of up to $2 \mathrm{~dB}$ are evident for all jet spacings. Data acquired at other supersonic conditions in Table II show similar interaction effects.

\section{Polar Directivity}

In the plane of the jets, some of the sound measured at a polar angle of $90^{\circ}$ emitted by the far jet travels through the near jet. In a simplified model, rays from the sound wave emitted by the far jet make a right angles with the jet axis of the near jet. As the observation angle increases, the incidence angle of the sound wave decreases to a theoretical limit where all incident sound is reflected. In the region where all incident sound is reflected, shielding and interaction effects are maximized. The transmission cut-off angle, $\theta_{c}$, refers to the maximum polar angle at which sound from the far jet can propagate into the near jet (Refs. 3 and 5). The transmission cut-off angle is calculated via the equation below where $c_{0}$ and $c_{1}$ refer to the ambient speed of sound and the speed of sound within the jets, respectively, and $\Delta M$ is the difference in Mach numbers of the free jet and twin jet.

$$
\theta_{c}=\cos ^{-1}\left(\frac{c_{0} / c_{1}}{1+\Delta M}\right)
$$

Overall sound pressure levels are used to evaluate polar directivity. The single jet plus $3 \mathrm{~dB}$ overall sound pressure levels were subtracted from the twin jet levels to give a change in overall sound pressure level ( $\triangle \mathrm{OASPL})$. A negative $\triangle \mathrm{OASPL}$ represents a reduction in noise level. Figure 9 shows the polar directivity of heated subsonic jets at three free jet Mach numbers at the in-plane and out-of-plane azimuthal angles for a $s / d$ of 3.245. For upstream polar angles from $40^{\circ}$ to $80^{\circ}$ little shielding and 


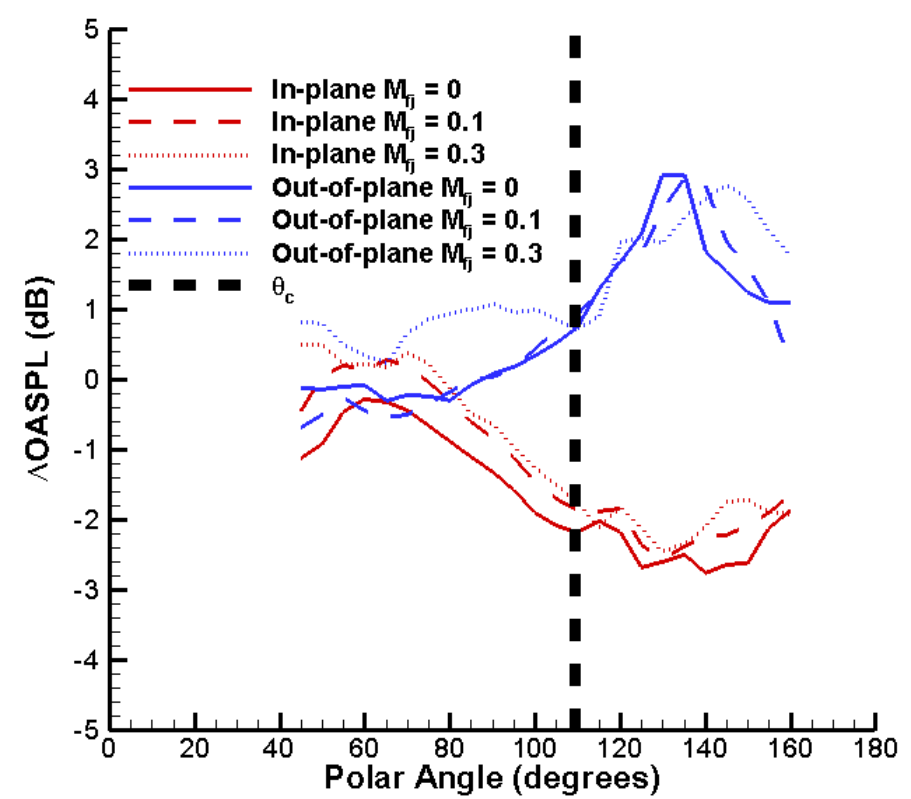

Figure 9.-Polar directivity of heated subsonic jets at a s/d of 3.245 with a NPR=1.7, NTR=3.11, $\mathrm{M}_{\mathrm{fj}}=0, \mathrm{NPR}=1.88$, $\mathrm{NTR}=3.12, \mathrm{M}_{\mathrm{fj}}=0.1$, and NPR=1.88, NTR=3.12, $\mathrm{M}_{\mathrm{fj}}=0.3$.

interaction effects are evident. For polar angles between $80^{\circ}$ and $140^{\circ}$ both shielding and interaction effects increase to a maximum $\triangle \mathrm{OASPL}$ of about $3 \mathrm{~dB}$. For angles greater than $140^{\circ}$ the $\triangle \mathrm{OASPL}$ magnitude decreases with increasing polar angle. In a simple 2D model, maximum shielding will occur for polar angles above $\theta_{c}$. In these experiments a slight increase in shielding is observed above $\theta_{c}$. For angles greater than $\theta_{c}$, interaction effects increase sharply with increasing polar angle up to $140^{\circ}$. As the free jet Mach number increases, shielding effects are decreased over all polar angles while the interaction effects are either maintained or increased. The polar directivity shown in Figure 9 is typical over the jet spacings in Table I and the subsonic and supersonic conditions in Table II.

\section{Azimuthal Directivity}

Acoustic data were acquired in the three positions shown in Figure 4 to evaluate azimuthal directivity. Figure 10 shows the azimuthal directivity of subsonic heated jets for each jet spacing in Table I. Overall sound pressure levels measured from the sideline azimuthal angle are expected to fall between measurements from the in-plane and out-of-plane angles. The sideline azimuthal angle acoustic levels fall between those of the in-plane and out-of-plane angles near the peak jet noise angle for all jet spacings except S3. For polar angles greater than $120^{\circ}$ and the S3 spacing, the sideline acoustic levels are equal to the levels measured in the plane of the jets. For angles less than $140^{\circ}$, polar directivity is highly affected by jet spacing. For the largest spacings (S5 and S8), sideline acoustic levels are greater than those for inplane and out-of-plane measurements for angles less than $110^{\circ}$. At the sideline angle, shielding effects are observed in the peak jet noise direction for all jet spacings. The azimuthal directivity shown in Figure 10 is consistent for all subsonic conditions in Table II. 

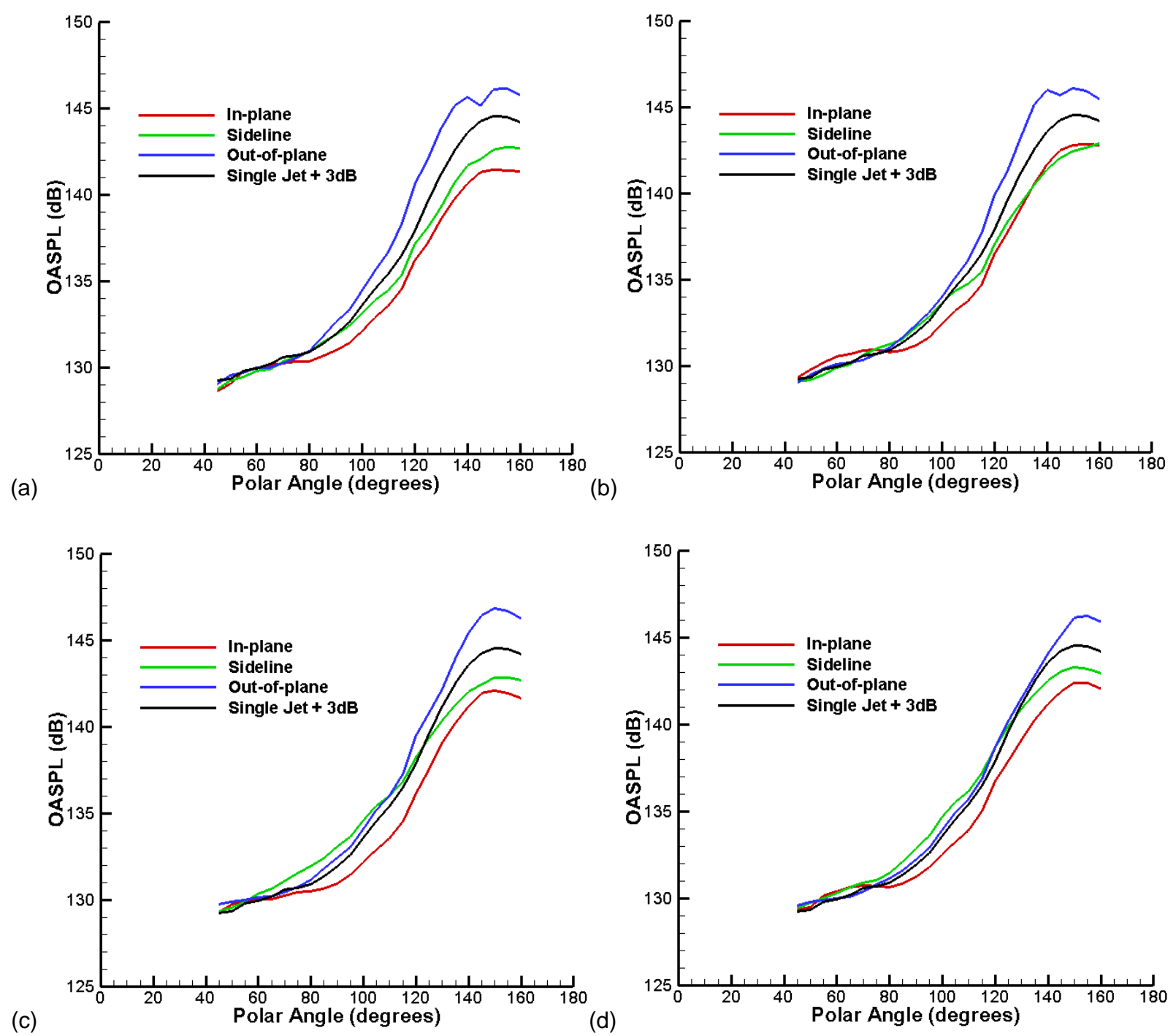

Figure 10._Azimuthal directivity of heated subsonic jets at a NPR=1.88, NTR=2.37, and $\mathrm{M}_{\mathrm{fj}}=0.1$ with a s/d of (a) 2.625 (S1), (b) 3.245 (S3), (c) 4.39 (S5), and (d) 5.54 (S8).

\section{Conclusions}

Shielding and interaction effects are concentrated in the peak jet noise direction where a $3 \mathrm{~dB}$ OASPL reduction or elevation is seen relative to single jet plus $3 \mathrm{~dB}$ levels, respectively. Twin jet interaction effects increase the sound pressure level up to $4 \mathrm{~dB}$ relative to a single jet plus $3 \mathrm{~dB}$ near the peak frequency in the peak direction. The increase is evident at jet spacings of $4.39 d$ and $5.54 d$ in the out-ofplane azimuthal angle. The out-of-plane measurements show that twin jet interaction effects can increase or decrease the radiated sound pressure level in the peak jet noise direction for a range of frequencies. As the free jet Mach number increases, shielding effects decrease over all polar angles while interaction effects either maintain or increase noise levels for all jet spacings. In the sideline orientation, shielding is observed in the peak jet noise direction for all jet spacings. 


\section{References}

1. Lasagna, P. L., and Putnam, T. W., "Engine Exhaust Noise During Ground Operation of the XB-70 Airplane,” NASA TN D-7043, 1971.

2. Balsa, T. F., Gliebe, P. R., Kantola, R. A., Mani, R., Stringus, E. J., and Wang, J. C. F., "High Velocity Jet Noise Source Location and Reduction Task 2 - Theoretical Developments and Basic Experiments," FAA-RD-76-79, 1978.

3. Gerhold, C. H., “Analytical Model of Jet Shielding,” AIAA Journal, Vol. 21, No. 5, 1983, pp. 694698, 1873.

4. Gerhold, C. H., and Kim, C. H., "Modified Jet Noise Source Model for Twin-Jet Shielding Analysis," Texas A\&M University, AIAA-83-0776, Atlanta, GA, Apr. 1983.

5. Yeh, C., "A Further Note of the Reflection and Transmission of Sound Waves by a Moving Fluid Layer," Journal of the Acoustical Society of America, Vol. 43, No. 6, pp. 1454, 1968.

6. Soeder, R. H., Wnuk, S. P., and Loew, R. A., “Nozzle Acoustic Test Rig User Manual,” NASA TM 2006-212939, 2006.

7. Amiet, R. K., "Correction of Open Jet Wind Tunnel Measurements for Shear Layer Refraction,” United Aircraft Research Laboratories, AIAA 75-532, Hampton, VA, Mar. 1975.

8. ANSI S1.26-1995 (R2004), "Method for the Calculation of the Absorption of Sound by the Atmosphere." 



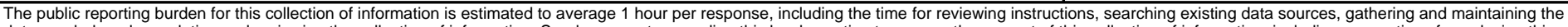

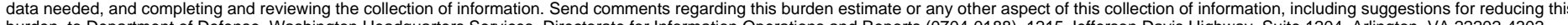

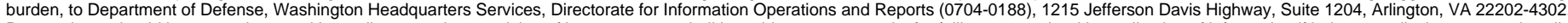

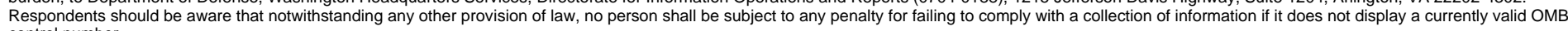

control number.
PLEASE DO NOT RETURN YOUR FORM TO THE ABOVE ADDRESS

\begin{tabular}{l|l|l}
\hline $\begin{array}{l}\text { 1. REPORT DATE }(D D-M M-Y Y Y Y) \\
01-02-2012\end{array}$ & $\begin{array}{l}\text { 2. REPORT TYPE } \\
\text { Technical Memorandum }\end{array}$ & 3. DATES COVERED (FrOm - To) \\
\hline
\end{tabular}

4. TITLE AND SUBTITLE

Aeroacoustic Experiments With Twin Jets

5a. CONTRACT NUMBER

5b. GRANT NUMBER

5c. PROGRAM ELEMENT NUMBER

6. AUTHOR(S)

Bozak, Richard, F.; Henderson, Brenda, S.

\section{5d. PROJECT NUMBER}

5e. TASK NUMBER

5f. WORK UNIT NUMBER

WBS 561581.02.08.03.18.16

7. PERFORMING ORGANIZATION NAME(S) AND ADDRESS(ES)

National Aeronautics and Space Administration

John H. Glenn Research Center at Lewis Field

Cleveland, Ohio 44135-3191

\section{SPONSORING/MONITORING AGENCY NAME(S) AND ADDRESS(ES)}

National Aeronautics and Space Administration

Washington, DC 20546-0001
8. PERFORMING ORGANIZATION REPORT NUMBER

E-18004

\section{DISTRIBUTIONIAVAILABILITY STATEMENT}

Unclassified-Unlimited

Subject Category: 71

Available electronically at http://www.sti.nasa.gov

This publication is available from the NASA Center for AeroSpace Information, 443-757-5802

\section{SUPPLEMENTARY NOTES}

\section{ABSTRACT}

While the noise produced by a single jet is azimuthally symmetric, multiple jets produce azimuthally varying far-field noise. The ability of one jet to shield another reduces the noise radiated in the plane of the jets, while often increasing the noise radiated out of the plane containing the jets. The present study investigates the shielding potential of twin jet configurations over subsonic and over-expanded supersonic jet conditions with simulated forward flight. The experiments were conducted with 2 in. throat diameter nozzles at four jet spacings from $2.6 d$ to $5.5 d$ in center-to-center distance, where $d$ is the nozzle throat diameter. The current study found a maximum of $3 \mathrm{~dB}$ reduction in overall sound pressure level relative to two incoherent jets in the peak jet noise direction in the plane containing the jets.

However, an increase of $3 \mathrm{~dB}$ was found perpendicular to the plane containing the jets. In the sideline direction, shielding is observed for all jet spacings in this study.

\section{SUBJECT TERMS}

Twin; Jet; Aeroacoustics

\begin{tabular}{|c|c|c|c|c|c|}
\hline \multicolumn{3}{|c|}{ 16. SECURITY CLASSIFICATION OF: } & \multirow{2}{*}{$\begin{array}{l}\text { 17. LIMITATION OF } \\
\text { ABSTRACT } \\
\text { UU }\end{array}$} & \multirow{2}{*}{$\begin{array}{l}\text { 18. NUMBER } \\
\text { OF } \\
\text { PAGES } \\
18\end{array}$} & \multirow{2}{*}{$\begin{array}{l}\text { 19a. NAME OF RESPONSIBLE PERSON } \\
\text { STI Help Desk (email:help@sti.nasa.gov) } \\
\text { 19b. TELEPHONE NUMBER (include area code) } \\
\text { 443-757-5802 }\end{array}$} \\
\hline $\begin{array}{l}\text { a. REPORT } \\
\text { U }\end{array}$ & $\begin{array}{l}\text { b. ABSTRACT } \\
\text { U }\end{array}$ & $\begin{array}{l}\text { c. THIS } \\
\text { PAGE } \\
\text { U }\end{array}$ & & & \\
\hline
\end{tabular}



